\title{
Interpretation of Space Through Metaphors
}

\author{
Ahmadova Ramila Isfandiyar Gizi \\ Azerbaijan University of Languages
}

\begin{abstract}
The present paper aims to analyze the metaphorical representation of space from a cognitive point of view in the English language. To achieve this purpose it mostly focuses on the investigation of space metaphors. It also presents certain ways in which metaphoric expressions represent space. Different view points of the lingusits are stated throughout the paper. The author attempts a better understanding of metaphors in terms of expressing space. The paper is fully representative of the state of the art in terms of language and space research, and point to new directions in terms of findings, theory and practice. This article is to a large extent about how these and other unconscious spatial activities relate to language and how language relates to space. This is an area of enquiry that has interested linguits, philisophers, and psychologists for a very long time and for a variety of reasons. In recent years cognitively oriented linguits have devoted more and more research, effort into trying to comprehend the space - language relationship especially space metaphors. The present paper aims to give an overview of some aspects of this effort, its current state. Examples provided contribute to demonstarte that space metaphors constitutes an essential part of our conceptual system.
\end{abstract}

Key words: metaphor, space, cognitive linguistics, text, language, conceptualization

\section{INTRODUCTION}

Spatial perception and cognition is fundamental to human abilities to navigate through space, define and spot objects, and track entities in motion . Moreover, research findings in recent decades find out that many of the mechanisms humans employ to achieve this are largely innate, providing abilities to store 'cognitive maps' for locating themselves and other locations, directions and routes. In this case humans are like many other species. However, unlike other species humans can employ language in order to represent space. The human linguistic ability combined with the human ability for spatial representation apparently results in abundant, creative and sometimes surprising extensions of represesentations for three-dimensional physical space. I have carried out a complex series of non-linguistic spatial tasks when I was planning to write the very article. Actaully, I was not aware of all of them , but they included probably; navigating my way visually to, into a book shop or library. Perhaps I employed some specifically space-related language: "Where can I find that book on language and space, metaphor and space?" and so on.

\section{DISCUSSION}

In the Kantian tradition space is a universal cognitive primitive, an " a priori form of intuition", that conditions all of our experience. It is then of particular interest to study the linguistic expression of space, since languages seem to capture and to make explicit the constraints of experience on the construction of spatial reference.(Hickmann \& Robert, 2006, p1).

In classical terms, metaphor is considered as a figure of speech, an adornment or elaboration of language, primarily intended for literary and poetic purposes. However, it may also appear in contexts other than literary works and poetry. It can be defined as "a figure of speech that 
associates two distinct things; the representation of one thing by another" (Murfin \$ Ray 2003, p.260). The tenor is the thing represented and the vehicle is the image used to represent the thing

According to cognitive linguists, space can be regarded as the most fundamental domain of human experience. (Evans \& Green, 2006, p.68) . Dominte (1970) states that in space we have position (state) and movement. Space is regarded as a fundamental conceptual domain employed in Conceptual Metaphor Theory, Cognitive Grammar,the Conceptual Structuring System Approach. The domain of space consists of matter which can be continuous or discrete, and locations occupied by matter. The nature of this domain derives from mechanisms central to perception which provide sensory experience thereby facilitating apprehension of physical aspects of our external physical environment. (Evans, 2007, p.202)

It is only relatively recently that linguists have begun to consider metaphors in a cognitive context (Kittay 1987, pp. 1-2). The first important, and still most often cited, study in the field is Metaphors We Live By, written by George Lakoff and Mark Johnson, published in 1980. Lakoff and Johnson (1980) are convinced that the elusiveness of meaning and the overlapping domains of metaphors have much more to do with each other than meets the eye. They wrote Metaphors We Live By with the conviction that metaphor is not only "pervasive in everyday life", but that "our ordinary conceptual system ... is fundamentally metaphorical in nature" (Kittay 1987, p.3), by which they mean that "most concepts are partially understood in terms of other concepts" (Kittay 1987, p. 56).

Metaphor is for most people a device of the poetic imagination and the rhetorical flourish - a matter of extraordinary rather than ordinary language. Moreover, metaphor is typically viewed as characteristic of language alone, a matter of words rather than thought or action. For this reason, most people think that they can get along well without metaphor. On the contrary, metaphor is pervasive in everyday life, not just in language and act, is fundamentally metaphorical in nature. (Lakoff \& Johnson, 1980, p. 4)

Taking as a starting point Lakoff's Theory of Metaphor (1993), it assumes that metaphor is not a purely linguistic phenomenon restricted to the poetic and literary uses of language, but an essential part of the conceptual system through which reality is conceived, and also an essential part of everyday language. Metaphor is conceptualized as a system of correspondences, a general mapping across conceptual domains. This system is manifested in language through metaphorical expressions. A metaphorical expression is "a linguistic expression (a word, phrase or sentence) that is the surface realization of such a cross-domain mapping" (Ibid, p.203).

Lakoff gives many examples of everyday concepts which are conceptualized via metaphor, among them emotional and abstract concepts used in everyday life, such as "space, time, quantity, state, change, action, change, purpose, cause, means, modality" (Ibid., p.212) According to Lakoff love for instance is conceptualized as a journey, in which two partners travel through a vehicle to reach a common destination or goal. A number of metaphorical expressions are derived from this mapping, such as "We're at a crossroads", "Our relationship has hit a dead-end street" or "We may have to go our separate ways" (Ibid., p.206). These metaphors are easily understood. Like many other emotional and abstract concepts, they are part of the system of everyday conceptual metaphors.

If metaphor is understood as an adornment of language, the first reason to use metaphors would serve as aesthetic purpose: to make the discourse more attractive, challenging, and 
beautiful. This can be perceived as one of the reasons to use metaphor, but not the only one. Ortony (1993), surveying the ideas of different authors, tries to give some provisional answers for the question of what metaphors are for. He points out that recent research suggests that "something new is created when a metaphor afford different ways of viewing the world" (Ortony 1993, p.5). In this sense, the use of metaphor is closely associated with the process of production of new language.

Space is used in metaphors to a remarkable degree. Spatial metaphors are those metaphors that have space as their source domain and map the image-schematic structure of space onto that of non-spatial and typically abstract target domains, thus enabling the user to talk about and perhaps even to think of those non-spatial domains in spatial terms. Examples are "the future is in front, the past is behind".

The first type of spatial metaphor has been called orientational and it was identified by cognitive metaphor theory. They are called orientational since most of these metaphors have to do with spatial orientation: up-down, in-out, front-back, on-off, deep-shallow. The characteristic feature of orientational metaphors is the use of abstract spatial configurations instead of specific locations or places, such as in(side) - out(side), up - down, left - right, or center - periphery, to give spatial orientation or structure to a non-spatial concept. Often, two opposite spatial conceptualizations are correlated, such as in up is more and down is less, or right is good with the correlate left is bad. However, this type of metaphor is often no longer recognized as a metaphor due to the conventionality of the underlying conceptualizations. Thus, orientational metaphors are very often non-deliberate and conventional, but sometimes available as a basis for new metaphorical expressions as well. (Fabian, 2016, p.454)

Upward orientation tends to go together with positive evaluation, while downward orientation with a negative one. However, positive-negative evaluation is not limited to the spatial orientation up-down. It has been pointed out that various spatial image schema are bipolar and bivalent. Thus , whole, center, link, balance, in, goal, and front are chiefly regarded as positive, while their opposites, not whole, periphery, no link, imbalance, out, no goal, and back are seen as negative. (Kovecses, 2010, p.40)

In contrast with this first type of orientational metaphors, which rely on abstract spatial relations and configurations, the next class of spatial metaphors employs more specific locations or places. Thus, metaphors belonging to this class can be located more easily, since they have a higher degree of metaphoricity. In the following classification, they will be arranged according to the cognitive extent of the metaphor, which may vary according to the text in which a particular metaphor occurs or to the author employing it. (Fabian, 2016, p.454) Orientational metaphors do not structure one concept in terms of another but instead organizes a whole system of concepts with respect to one another. These spatial orientations arise from the fact that we have bodies of the sort we have and that they function as they do in our physical environment. Orientational metaphors give a concept a spatial orientation; for example, happy is up. The fact that the concept HAPPY is oriented up leads to English expressions like "I'm feeling up today".(Lakoff \& Johnson, 1980, p.15)

The first, and most basic, type of this class of spatial metaphor is the use of a concrete or specific space or location on the lexical level when spatial characteristics are applied to a single word or phrase. This occurs when a non-spatial term is referred to, or used, as if it were a place or space, or when one spatial term might be metaphorically conceived of in terms of another, different space or place. These metaphors result from a simple transfer of vehicle to tenor 
without relating the whole conceptual domains from which they are taken through multiple mappings and are therefore isolated, i.e. non-conceptual. (Fabian, 2016, p. 454)

A second, and more extensive, type of spatial metaphor is the use of a specific space or location on the conceptual level. While the conceptual metaphor must still be instantiated on the lexical level of individual linguistic metaphors, it is not a single word, but a whole concept which is given spatial properties by means of metaphoric transfer. This happens when a spatial metaphor on the lexical level can be regarded as a mapping of a more extensive underlying conceptualization. In the case of this second type of spatial metaphor, it is insufficient to view tenor and vehicle as isolated lexical entities, but they have to be regarded as parts of their respective domains. (Fabian, 2016, p 455)

Thus, this type of metaphor entails multiple transfers, i.e. mappings, which form conceptual metaphors with a spatial source domain being correlated with a target domain. For such mappings to qualify for the category of spatial conceptual metaphor, the source domain must be spatial while the target domain may, but need not, be a spatial concept.

The most extensive type of spatial metaphor can be found in cases where a specific space or location is used metaphorically on a broader textual level. It is possible for a longer narration or even a whole text to function as a spatial metaphor (something like a macro-metaphor). Assuming the traditional definition of allegory as 'extended metaphor', this type could also amount to and be described as spatial allegory. (Fabian, 2016, p.455)

Lakoff speaks of two main categories of metaphors, conceptual metaphors and image metaphors. Conceptual metaphor "maps one conceptual domain onto another, often with many concepts in the source domain mapped onto many corresponding concepts in the target domain" (Lakoff and Johnson 1980, p. 229). Image metaphors work with images, instead of concepts, mapping "one conventional image onto another [...] they are "one-shot" metaphors: they map one image onto another image" (Ibid., p. 229). The distinction between image metaphor and conceptual metaphor is not clear-cut, as very often a conceptual metaphor is based in knowledge derived from image metaphors.

Spatial metaphors are used to help people comprehend abstract concepts in terms of perceptual experience. For example, 'feeling high' or 'feeling down'. A result of this strategy is that metaphor can bias perception and decision making. For example, consistent with metaphors for effect and spatial perception (up=good, down=bad), people more readily identify positive things when high in location. North and south are abstract concepts, which are also tied by metaphor to spatial perception (north=up, south=down). Based on this, the authors hypothesized that, by virtue of a shared mapping with up and down, north and south may have affective associations (north=good, south=bad) that bias decisions related to housing in terms of location preference and expectations of where others live.

Lakoff and Johnson mention several types of spatial orientation (front-back, in-out, near-far) (Lakoff and Johnson, 1980, p.56). However, the one they treat in detail is up-down (Lakoff and Johnson, 1980, pp. 14-21). They look at ten different ways that up-down metaphors are used in English and give a number of example sentences for each, with categories like happy is up; sad is down (You're in high spirits.) or more is up; less is down (If you're too hot, turn the heat down) (Lakoff and Johnson, 1980, pp. 15-16). 
Most examples of UP-DOWN metaphors in English are taken from George Lakoff and Mark Johnson's book, Metaphors We Live By (1980). Take a look at the following examples drawn from the mentioned book:

Happy is up, sad is down /I am feeling up// - I feel well /I am feeling down// - I feel dejected, I feel downcast /My spirits rose// - My mood improved, My mood lifted / My spirits sank// - My mood got worse, My mood sank

Conscious is up, unconscious is down

/I am up already// - I have already got up, I am already up

/I dropped off to sleep// - 'I went to sleep', 'I went into sleep'

/He is at the peak of his health on //- 'He is bursting with health', 'He is in the best of health'

Health and life are up; sickness and death are down

/His health is declining// - 'His health is getting worse' , 'His health is going down'

More is up, less is down

/Prices rose// - 'Prices have risen', 'Prices became higher'

/The rate of inflation fell// - 'Inflation rate has sunk'

/The stock market jumped// - 'The stock market went up' 'The stock market climbed'

Good is up, bad is down

/He does high quality work// - 'He does first-class work' 'He does quality work'

/He sank in my estimation// - 'He was lowered in my eyes' 'He sank in my eyes'

Location: Points in space

He had a special place in her heart.

Tom had finally come to the point of conclusion.

The CPU is the central hub of the computer.

The height of one's career.

Deep despair.

\section{Portals: Linking spaces}

Your browser is your doorway to the internet.

Education is a gateway to success.

Tolerance is the window to peace.

Conduits: Linking locations

On the road to peace

Life in the fast lane.

Following the path of enlightenment.

Azerbaijan is the towering beacon of tolerance in the region.

Spaces: 3-D locations

In the bowels of the ship

A child needs room to grow.

Her mind was caged by depression.

Movement: Travel in space

The little girl followed in her mother's footsteps. 
The business was about to take flight.

His head was spinning with excitement.

Perimeters: Limit of a space

A middle-aged woman was hitting her head against a brick wall.

The elderly woman had returned from the edge of death.

Sports rules set the boundaries of fair play.

\section{Encapsulation: Housing space}

The ground was covered with a blanket of snow.

The old detective wrapped up the mystery.

He had become a shell of a man. (Lakoff \& Johnson, 1980, pp.15-17)

\section{CONCLUSION}

On the basis of the above mentioned examples, we can suggest that most of our essential concepts are organized in terms of metaphorical concepts. Furthemore, there is an internal systemacity to each spatialization metaphor . For example, SAD IS DOWN defines a coherent system rather than a number of isolated and random cases.

It is hoped that this work increases our understanding of such notions as space and metaphor by discussing space metaphorically. Thus from this paper you now know that the category of space can be treated metaphorically. After reading an article, you can make an informed judgement about whether the paper would be worthwhile to read. Consequently, we have tried to offer a possible view on space, spatial metaphors in cognitive linguistics. We can only hope that the paper was worth the effort.

\section{References}

Black, M. 1955 . Metaphor. Proceedings of the Aristotelian Society 55 , 273-294.

Evans, Vyvyan. 2007. A Glossary of Cognitive Linguistics. Edinburgh: Edinburgh University Press

Goatly, A. 2011 The Language of Metaphors. London and New York: Routledge

Imre, A. 2012. Space in Cognitive Linguistics. Acta Universitatis Sapientiae, Philologica

Fabian H, et al. 2016. Spatial Metaphors of the Ancient World: Theory and Practice

Hanks P. 2006. Metaphoricity is Gradable. In CorpusBased Approaches to Metaphor and Metonymy. Ed. by A. Stefanowitsch and S. Th. Gries. Trends in Linguistics 171. Berlin and New York: De Gruyter, 17-35.

Hickmann ,M. \& Robert, S. 2006. Amsterdam/Philadelphia . John Benjamin Publishing Company.

Kittay, E. F. 1987. Metaphor: Its Cognitive Force And Linguistic Structure. Oxford: Clarendon Press

Kovecses, Z. 2010. Metaphor. A Practical Introduction. 2nd ed. Oxford: Oxford University Press

Kovecses. Z. 2005. Metaphor in Culture. Universality and Variation. Cambridge: Cambridge University Press

Lakoff, G. \& Johnson, M. 1980. Metaphors We Live By. Chicago: University Press

Lakoff, G. 1993. The Contemporary Theory of Metaphor. In Metaphor and Thought. Ed. by A. Ortony. 2nd ed. Cambridge: Cambridge University Press, 202-251.

Lakoff ,G. \& Turner,M. 1989 More than Cool Reason: A Field Guide to Poetic Metaphor. Chicago and London: The University of Chicago Press

Murfin, R.C., \& Ray, S.M. 2003. The Bedford Glossary of Critical and Literary Terms (2nd edition) . Boston: Bedford/St. Martin's

Ortony, A. 1993. Metaphor and Thoughts. New York, NY, US: Cambridge University Press

Pragglejaz Group (Peter Crisp, Raymond Gibbs, Alice Deignan, Graham Low, Gerard Steen, Lynne Cameron, Elena Semino, Joe Grady, Alan Cienki, and Zoltán Kövecses). "MIP: A Method for Identifying Metaphorically Used Words in Discourse". Metaphor and Symbol $22,1-39$. 
Raymond W. Gibbs Jr. 1996. Why Many Concepts are Metaphorical. Cognition 61 , 309-319.

Rolf, E. 2005. Metaphertheorien. Typologie - Darstellung - Bibliographie. Berlin and New York: De Gruyter 